Área Abierta. Revista de comunicación

audiovisual y publicitaria

ISSN: 2530-7592

\title{
El tiempo del cínico. Acerca del héroe de la ficción televisiva
}

\author{
Giancarlo Cappello ${ }^{1}$
}

Recibido: 19 de julio de 2016 / Aceptado: 24 de noviembre de 2016

Resumen. El texto se detiene a observar la peculiar construcción de algunos de los protagonistas más destacados de esta última edad dorada del drama televisivo, contrastando sus características con aquellas que hasta hace poco daban forma a una cierta interpretación o idealización de lo que debía ser un héroe moderno. Esta nueva y cada vez más recurrente concepción de base respondería al aggiornamento de la cultura popular con el "espíritu del tiempo" que la atraviesa: un tiempo desencantado y de perplejidades, pero, sobre todo, cínico.

Palabras clave: Ficción sonora; novela; cine; adaptación; transtextualidad; transcodificación; Extraños en un tren

\section{[en] Age of the Cynical. On TV Fiction Hero}

\begin{abstract}
The article analyzes the peculiar construction of some of the most outstanding leading characters in this recent Golden Age of TV drama, by comparing their characteristics to those that until very recently shaped the performance of an ideal modern hero. This new and increasingly recurrent basic concept would correspond to an aggiornamento of popular culture in line with the current "spirit of times": a time full of disenchantment and bewilderment, but also of cynicism.
\end{abstract}

Keywords: TV Series; Hero; Modernity; Cynicism

Sumario. 1. Introducción. 2. Metodología. 3. Antecedentes. 4. Una ficción desbordada. 5. Discusión. 6. Conclusiones. 7. Bibliografía

Cómo citar: Cappello, G. (2017) El tiempo del cínico. Acerca del héroe de la ficción televisiva, en Área Ábierta. Revista de comunicación audiovisual y publicidad 17 (2), 155-166. http://dx.doi.org/10.5209/ ARAB.53240

\section{Introducción}

Cada periodo de la historia ha dado origen a un héroe específico, a un hombre distinto, capaz de reunir las cualidades y virtudes más apreciadas de su época. Desde las leyendas hasta los medios masivos, estos seres especiales han dejado su estela como vestigios de un tiempo memorable. Los hay todopoderosos e inmortales, innobles y pueriles, ridículos, solidarios y perdedores. Si alrededor del héroe orbitan valores y

$1 \quad$ Universidad de Lima (Perú)

E-mail: gcappello.f@gmail.com 
premisas como paradigmas que hay que alcanzar, si el héroe pertenece a la instancia de los vencedores y su imagen circula como una estampa ilustre, cabe preguntarse ¿qué ha pasado con el héroe de este siglo veintiuno?

En este trabajo ensayamos una respuesta a la luz de las espléndidas teleseries norteamericanas que en los últimos quince años han configurado un nuevo tiempo para la televisión dramática. Siguiendo la estela de György Lukács y Lucien Goldmann, interesa indagar en la figura del héroe como reflejo de las configuraciones sociales de su tiempo. Mientras que para Lukács (1979) el protagonista es un individuo problemático en un mundo hostil y contradictorio, Goldmann lo describe, más bien, como un sujeto capaz de establecer una estructura mental coherente que se corresponde con una visión del mundo. "Tal estructura no puede ser elaborada más que por el grupo, siendo el individuo únicamente el elemento capaz de desarrollarla hasta un grado de coherencia muy elevado" (Goldmann, 1972; 27).

Este análisis entiende como héroe al protagonista de la historia, es decir, escapa a la noción restringida que lo vincula a las características épicas. Siguiendo a Villegas, "es preferible asumir que héroe es el personaje protagonista, que generalmente representa el sistema de valores propuestos intrínsecamente en el texto" (Villegas: 1978). De manera más particular, resulta pertinente la idea de Noé Jitrik, que lleva más allá esta noción al considerar héroes a todos los personajes que describen un recorrido para alcanzar sus objetivos, entendiendo que en tiempos donde los valores epistemológicos resultan relativos no existe un único valor que se yerga por encima de los otros (Jitrik:2001).

Cada tiempo ha reclamado de los héroes características y virtudes particulares, afectando su mundo interior, su perspectiva psicológica y espiritual acerca del mundo. Sobrevivir a la muerte, por ejemplo, burlarla, escamotearle su derecho a disponer de nosotros, ha supuesto desde antiguo uno de los grandes méritos del heroísmo. Sin embargo, la muerte de hoy no es la misma vieja Parca de antaño. Hoy, al héroe la muerte le sienta bien, pero ya no en la dimensión trágica de su esencia, sino en un sentido cotidiano. Acaso sigue siendo una relación tensa, pero también imprecisa, difusa, maldita, cargada de amor-odio, de mutua complicidad y mutuo sabotaje, sobre todo cuando la tragedia no consiste en morir sino en permanecer con vida.

En ese sentido, nos interesa analizar las premisas sobre las que se fundaría el prototipo heroico que circula y se asienta en algunas de las más exitosas teleseries norteamericanas de hoy. Porque si el héroe se forja en sintonía con los flujos sociales e ideológicos predominantes, el héroe es un hombre de su tiempo.

\section{Metodología}

Este análisis se enmarca en el entretenimiento audiovisual, en particular en las teleseries de ficción. El ámbito de estudio se ha ceñido a un grupo de producciones norteamericanas que desde el año 1999 han revitalizado la ficción televisiva. Aunque también se hace mención a otras producciones, el análisis recae básicamente sobre The Sopranos, Mad Men y Breaking Bad, elección que queda justificada por tratarse de producciones que han llegado a su fin y, por ende, se prestan para un análisis firme, sin posibles eventos futuros que modifiquen la trama o el arco dramático de sus personajes. 
Para enfrentar este trabajo se ha optado por una metodología cualitativa que combina la exploración interdisciplinar y fusiona el análisis del discurso con la narratología.

Nuestra hipótesis sostiene que el cinismo se ha impuesto por sobre las grandes fórmulas del heró́smo del siglo veinte para narrar este primer tramo del siglo XXI. Nos referimos a un cinismo en la línea de Sloterdijk, entendido como "la conciencia infeliz que se sabe perdedora, pero no da su brazo a torcer" (2003: 137). A la luz de esto, el foco de atención está puesto en las acciones y esfuerzos de los protagonistas por conseguir sus propósitos, pues este cínico es absolutamente consciente de su realidad y sabe cómo y cuándo usar la mascarada.

\section{Antecedentes}

El mundo ha cambiado. John Le Carré tiene una frase que resulta ilustrativa, la pone en boca de Alec Leamas, el protagonista de una de sus novelas: "Hoy en día se necesita ser un héroe para ser simplemente una persona decente". Le Carré, arquitecto de intrigas donde el espía dista mucho del protagonista arrojado, valiente y seguro, sabe que para trabar empatía con sus personajes no hace falta presentarlos como infalibles o todopoderosos, sino como sagaces burócratas que jamás han disparado un arma ni han planeado un asesinato. Es decir, como tipos carentes de magia, prosaicos, cotidianos. Porque si algo reconforta hoy, es la idea de que seres comunes puedan ser capaces de grandes hazañas. El mundo ha cambiado y los héroes también.

La modernidad supuso un desplazamiento crítico alrededor del heroísmo. Si el héroe romántico miraba fuera del ámbito social -a la naturaleza y a un pasado perdido - el realismo fundó un escenario que solo podía ser social. En un tiempo pragmático, cuya concepción de base dice que solo es verdadero aquello que funciona, el héroe moderno se vinculó más que nunca a la verosimilitud y pasó de ser un elegido a convertirse en un sujeto ilustrado que encaraba el futuro seducido por el progreso tecnológico y científico (Argullol: 1990). Su proverbial individualismo, su astucia, sus ambiciones y sus deseos terrenos, hicieron que no necesitara más de la intervención divina o de algún mago: su mejor golpe pasó a ser el argumento contingente; su arma favorita, el ingenio multiforme.

Cuando adquirieron protagonismo, el cine y la televisión contribuyeron a reproducir y asentar esta idea. De hecho, el éxito de un texto como El viaje del escritor no solo sirve como demostración, sino que funciona como mecanismo de normalización. Su autor, Christopher Vogler, se convirtió en un referente para la industria al ofrecer un proceso formal que sintetizaba los mecanismos narrativos del mito, los relatos orales y los cuentos de hadas a partir de los estudios de Joseph Campbell y Carl Jung. Vogler desplazó el componente mágico religioso y las honduras del psicoanálisis y los sustituyó por un proceso de trasformación interior - a journey into fears - Entendió que si los personajes se concebían como una expresión del inconsciente colectivo todas las hazañas quedarían reducidas a pulsiones mecánicas e ingobernables, de modo que puso énfasis en la duda - para marcar distancia con el héroe de dotes excepcionales que cumple un destino categórico- $-\mathrm{y}$ fundó un modelo donde el héroe siempre se ve superado por las circunstancias y debe luchar en un contexto desfavorable, que agranda su valor y sacrificio. En este esquema, las ideas del self-made man y la ética protestante del trabajo - la necesidad de trabajar duro 
como componente del atractivo y el éxito personal — reemplazaron definitivamente a la predestinación y promovieron al hombre común a la categoría de héroe.

Los medios de masas trasformaron la vida cotidiana en una épica moderna, muy en consecuencia con un siglo veinte que invirtió más esfuerzos que ninguno en empoderar al individuo, en ganarle libertades y en reivindicar a las minorías ante un sistema inicuo que pretendía, precisamente, el sometimiento de esas libertades. Sin embargo, entrados ya en el siglo veintiuno, y a la luz de esta última edad dorada de la ficción televisiva, los relatos empiezan a tener como protagonistas y antagonistas, a la vez, a tipos que se revelan como fingidores audaces e hipócritas desalmados, como si los viejos héroes hubiesen perdido la guerra y debieran sobrevivir en un paisaje distinto y distante de la utopía.

El mundo que se representa en las teleseries de hoy no es más ese lugar donde jamás cunde la zozobra porque el héroe está ahí para resolver cualquier problema. Por el contrario, en ese mundo, la intranquilidad se asume sin mayores sobresaltos y los héroes tientan - la más de las veces - empresas perdidas de antemano. De ahí que nos interese la crisis de sentido que experimentan, pues entendemos que esa crisis es la causa principal del arco dramático que describen y que hace que la concepción clásica del héroe cambie de manera determinante.

\section{Una ficción desbordada}

Lo más destacable de esta nueva generación de teleseries es el feliz equilibrio que exhibe entre arte y negocios. Es una televisión producida con hambre de gloria económica, pero sin descuidar el interés argumental y estético, empeño que ha resultado en algo pocas veces visto: la satisfacción del público, de la crítica y de la industria del entretenimiento. La ampliación de la competencia, la consiguiente necesidad de buscar imagen de marca a través de una producción propia, así como la sofisticación en la distribución del contenido, han sido factores que contribuyeron decididamente a forjar el drama contemporáneo (Cascajosa, 2009; Pérez, 2011; García Martínez, 2012).

Pero, más allá de cualquier consideración, la razón de base de este suceso descansa en las historias, en las tramas que despliegan, en los modos de narrar, rn los temas que alientan y en esa relación 2.0 que plantean a sus espectadores. Todo esto en un entorno de libre competencia donde la práctica del narrowcasting ha otorgado carta blanca para la experimentación y la innovación: nuevas historias para nuevos públicos que conquistar, situación que ha derivado en el surgimiento de una audiencia técnicamente capacitada y dramáticamente exigente (Mittel, 2007). Como señala García Martínez (2012), se ha abierto tanto el abanico de temáticas posibles que difícilmente alguien no podría encontrar una propuesta que sea cercana a sus intereses.

Concepción Cascajosa (2006) ha sintetizado algunas de las características esenciales de este nuevo drama: la reivindicación del tabú, plasmada por ejemplo, en la amoralidad de Tony Soprano, en la representación del sexo en Spartacus o en los excesos de Vic Mackey en The Shield (FX 2002-2008); la hibridación de géneros, capaz de lograr productos como Cold Case (CBS 2003-2010), una sólida aleación entre drama familiar y policial, o Deadwood, un western reconvertido en drama urbano; finalmente, la renovación y actualización de técnicas narrativas a 
través de estructuras con distintos niveles de lectura, vacíos de información y tramas laberínticas que alimentan la expectativa.

Se trata de historias que exploran los límites y reconvienen la actualidad, integran lo cotidiano en sus distintos ámbitos y son capaces de cuestionar, provocar, banalizar o alentar temáticas de diversa índole que conectan directamente con la experiencia individual. En estos relatos, confluyen no solo la ideología, las prácticas, las filias y las fobias de la sociedad contemporánea, sino también otras narraciones, otras sensibilidades, otras series; guiños a la cultura pop, a los videojuegos y a la tradición clásica. En suma, es un inmenso juego que acerca la experiencia narrativa a un palimpsesto (Cappello, 2015).

Las teleseries se han transformado en eficientes dispositivos para contar historias, tal cual lo fueron en su tiempo el folletín y la novela por entregas, capaces de generar el mismo nivel de expectativa que cundía en los puertos de Boston y Nueva York ante el arribo de un nuevo capítulo de Dickens. Las series de televisión parecen haber tomado la posta en la tarea de forjar el imaginario popular. Si la Rusia decimonónica palpitó con Crimen y Castigo a través de las entregas de El Mensajero, el mundo de hoy conoció a Walter White a través de AMC. Si Salgari hizo que los lectores se estremecieran con Sandokan, los televidentes de hoy hicieron lo propio con Jack Bauer, el protagonista de 24. Si Balzac quiso narrar la sociedad parisina de su tiempo a través de libros como Las ilusiones perdidas, David Simon hizo igual a través de The Wire y el retrato descarnado de la sociedad norteamericana que compone.

Estamos ante relatos cuya variedad y permanente innovación los convierte en material elusivo para cualquier formalización. Sin embargo, tentaremos una aproximación a los protagonistas de los títulos seleccionados con la intención de develar la ponderación que tienen del mundo y de sí mismos.

\section{Metodología}

Muchas teleseries parecen descartar la idea de hacer triunfar a un personaje para, sencillamente, describirlo en medio de la confusión en que se desenvuelve; así, dejan de lado cualquier forma de trascendencia y universalidad para abrazar la singularidad y la contrariedad de los conflictos que lo atraviesan. De ahí que varios de los programas más sintonizados tengan como protagonistas a personajes que practican el funambulismo en los bordes de lo legal, de lo social y de lo moral, es decir, a seres opacos, apenas a gusto con la talla de vida que les ha tocado vivir y cuya suerte intentan revertir.

The Sopranos y Mad Men son dos ejemplos ilustrativos. Los eventos que desarrollan resultan importantes no en la medida que conducen a un desenlace, sino en tanto desagregan más y mejor a los personajes y sus tribulaciones. La ausencia aparente de una trama de base permite concentrarse en los detalles y sumergirse en un naturalismo cotidiano que dibuja el derrotero cansino de Tony Soprano y Don Draper. Ambos, cada uno a su modo, tienen claro que el poder y el éxito que han acumulado son efímeros, insustanciales, casi un logro de pacotilla. Tony es capaz de verse a sí mismo como un big boss, pero es consciente de que su poder apenas le encumbra como una especie menor en la cadena alimenticia de un sistema cuya crueldad y corrupción le estremecen y le hacen sentir indefenso. De hecho, su mayor espanto consiste en acabar convertido en un don nadie, en un sujeto cualquiera, sin 
el Cadillac ni la pistola que le venden la ilusión de seguridad y victoria. "No esperes felicidad [aconseja Tony]. Tus amigos te traicionarán y nadie recordará tu nombre. Morirás en tus propios brazos".

Por su parte, Don Draper, el protagonista de Mad Men, asoma como un modelo de triunfo. Es un hombre blanco en la etapa más racista de los años 60, es guapo, es un profesional de éxito cuya elegancia y sofisticación proyectan la seguridad que Tony acaso hubiera deseado para sí. Sin embargo, cuando no debe trabajar y sonreír, incluso cuando todo marcha bien, la domesticidad marchita el esplendor, su vida familiar necesita de amantes que enciendan su deseo de vivir y duda del reconocimiento que ha merecido su genio como publicista. Es decir, cuando Don Draper enfrenta la realidad de que su vida jamás alcanzará el ideal que venden sus anuncios publicitarios, Mad Men deja en claro que el mundo - traducido en confort, estatus, progreso a nivel personal y social - es incapaz de generar la felicidad prometida y apenas concede un roce frío, precario, distante.

Es la pérdida de la inocencia, la expulsión del paraíso o lo que pretendía ser su ideal. En este marco, los personajes no hacen sino demostrar que la utopía es una farsa y que el cambio es inviable. "¿Sabes lo que es la felicidad? [explica Don] La felicidad es el olor de un coche nuevo. Es ser libre de las ataduras del miedo. Es una valla a un lado de la carretera que dice que lo que estás haciendo, lo estás haciendo bien".

Asistir a las vivencias y peripecias de estos personajes es aproximarse a la macilenta luz de un proyector que exhibe los trazos de una radiografia turbadora. Se trata de universos ficcionales que son la metáfora de un tiempo donde aquello que era claro, ordenado y prometedor se vuelve repentinamente incomprensible. Es una época desconcertante para los viejos héroes, pues recorren una realidad inestable donde no existe un punto de referencia a partir del cual organizarse, donde la explicación definitiva de los fenómenos ahora se proyecta como un territorio plagado de interpretaciones.

"Commendatori", el cuarto capítulo de la segunda temporada de The Sopranos, ilustra este punto a propósito del viaje que Tony, Paulie y Christopher hacen a Nápoles para vender autos de lujo a la Camorra. Cada personaje se convierte en un testimonio que explora la precariedad de las bases a partir de la cual se funda una identidad, una pertenencia, un sentido de clan. Para Christopher, New Jersey y Nápoles resultan intercambiables, él sigue prefiriendo los viajes con heroína, no le interesa interactuar con los locales, ni siquiera indagar en sus orígenes familiares, algo que Paulie, por el contrario, quiere sacar a relucir con esfuerzos patéticos que lo llevan a hacer el ridículo y a refugiarse en brazos de una prostituta del mismo pueblo de su abuelo. Tony se interna con éxito en la Camorra, pero tampoco puede evitar cotejarse como mafioso, como hombre de familia y como machista redomado al tener que negociar con la mujer que lleva las riendas del poder. El viaje a Nápoles descompone lo que significa ser italoamericano, esa identidad idealizada a la luz de las películas de la mafia que los personajes idolatran e instalan en la mitología de su estirpe. Después de Nápoles, ser italoamericano para The Sopranos es una levedad, pero también algo fantástico, en todo el sentido de la palabra.

A buena parte de este nuevo drama televisivo - al que, además, hemos encumbrado como referencia de calidad (Thompson, 1997; Feuer, 2003) — no le seduce el vigor de este siglo veintiuno, sus triunfos técnicos, su híper conexión o su exacerbada movilidad, sino sus fisuras invisibles, sus esquinas feas, esas calles oscuras por las 
que pocos se animan a cruzar. En estas teleseries, los héroes asoman como hombres pequeños, inconsistentes, desprovistos del aparato ideológico y social que antes garantizaba las reglas para tentar la victoria. Tony Soprano y Don Draper son dos descreídos muy conscientes de su naturaleza frágil, como si hubieran entendido "que la vida es trágica y que se desarrolla también en lo horroroso, en lo monstruoso, en el cruce de caminos entre la desesperanza y el desencanto, la felicidad y los sueños" (Bárcena 2001:13).

\subsection{Los héroes cansados de la modernidad}

El flujo constante de este tipo de historias y su aceptación entre el público sugieren una sintonía colectiva con personajes moralmente cuestionables o villanos, a los que por extensión se suele denominar antihéroes. De acuerdo con Mieke Bal (1999), la condición de antihéroe normalmente está asociada a la figura del antagonista — quien se opone a lo pactado como heroico-, pero también puede designar al personaje que, aun difiriendo en apariencia y valores, cumple la función heroica protagónica. Esta segunda acepción es la que nos interesa destacar, ya que señala características singulares para los protagonistas, "dotándoles de una individualidad dramática y una verosimilitud que el lector no tiene necesariamente que compartir, sino solo comprender" (Baal, 1999: 34).

En ese sentido, las teleseries tienen la inmensa capacidad de organizar un conocimiento amplio del carácter de sus personajes, lo que reditúa en una empatía que identifica mental y afectivamente al auditorio con los protagonistas. La fuerte focalización de Breaking Bad sobre Walter White, por ejemplo, permite que se establezca un compromiso con su enfermedad y sus angustias. La empatía es tal que el público acaba construyendo un sistema de valores particular para juzgar sus acciones (Echart y García, 2013). El tercer episodio, “... And the bag's in the river", resulta fundacional en esta relación. Walter se agobia decidiendo si debe o no matar a Krazy Eigth, el traficante de drogas que está prisionero en su sótano. En una columna lista los argumentos a favor de no hacerlo, sus motivos van desde el estrés postraumático hasta los principios judeocristianos que le indican que él no es un asesino. En la columna de al lado, sin embargo, anota la única razón para liquidarlo: si el traficante queda con vida, matará a toda su familia. Desde ese momento, Walter se instaura como el más débil dentro de un sistema infecto, no solo en el aspecto criminal, sino también profesional - participa de un sistema educativo decadente que no valora los méritos ni la figura del intelectual - y social — dado por los enormes costos del tratamiento contra el cáncer y la incertidumbre con respecto al futuro de su familia sin él- En medio de todo ello, Walter no solo aparece como una víctima, sino como aquél que encarna los valores socialmente pautados como positivos, pues está defendiendo lo más importante para un hombre: su familia.

Walter ingresa al mundo de las drogas amparado en una excusa irrebatible. Pero, en cierto punto, deja de responder a las motivaciones iniciales y se embarca en una espiral criminal que, sin embargo, parece justa: es su revancha, su desquite con ese mundo que lo condenó a ser un profesional anónimo y anodino. El público le sigue hasta el último episodio en función de un pacto moral renovado convenientemente y acepta su final sin condenarlo, pues es capaz de comprender la confesión final de Walter a su esposa, cuando explica que el resorte que lo llevó a convertirse en un criminal fue la terrible, honesta y egoísta satisfacción de saberse por primera vez 
bueno, acaso el mejor, en aquello que hacía. Puede parecer que en Breaking Bad hay menos cuestionamientos al sistema que en Mad Men o en The Sopranos, pues describe la forja de Walter por lograr la posición que Don Draper ha ganado y que Tony Soprano heredó, pero en la cuestión de fondo subyace la misma crítica: como el tren que llevaba a la utopía jamás llegó buscando a Walter, él decidió convertirse en el vehículo de su propio ascenso, echando mano de sus habilidades y fundando sus propias reglas.

En Breaking Bad, la idea de una modernidad construida sobre la base del hombre y la razón erosiona a tal punto que Walter White, en la línea de Lyotard (1998), reniega de ese metarrelato a la luz de la evidencia empírica que ofrece su propia experiencia como hombre de ciencias, descolocado ante unos fundamentos inoperantes que debían ofrecer seguridad y sentido a todas las manifestaciones de la realidad.

Hasta el advenimiento de esta nueva edad dorada de la televisión, el planteamiento de los dramas televisivos se traducía en la exposición de un mundo en equilibrio que entraba en crisis, pero que al final volvía al statu quo, al orden, a la perennización de lo que inicialmente se planteó como lo adecuado, como el deber ser. Pero ante la incursión de estos héroes malvados en el primer plano de las historias - respaldados por un público empático que los acompaña semana a semana-, aparecen nuevos pliegues, otros ángulos, otras consideraciones acerca del mundo y de las cosas que obligan a desviar el curso que llevaba a la restitución del orden para encaminarse, de manera inquietante, a una nueva versión de ese mundo. Como si el periplo de estos personajes hubiera servido para develar las miserias evidentes que solían omitirse, precisamente, para sostener el statu quo.

Los cimientos físicos y morales de lo social se socavan en muchos de los nuevos dramas: la corrupción tiñe de forma irremediable a los personajes y todos asoman en el paisaje con pecados, cuentas pendientes o faltas de algún tipo. Incluso los villanos aparecen con más de un perfil que los convierte en seres heridos. El protagonista de Dexter, por ejemplo, fue testigo del asesinato de su madre con una motosierra, permaneció dos días dentro de un contenedor en estado de shock junto a los restos de su madre y de otras víctimas. En virtud de ello, ahora es un serial killer, pero tiene un código que le permite asesinar solo a aquellos que merecen morir y que, por distintos motivos, jamás serán sancionados. Don Draper es un impostor que debió tomar la identidad de otra persona para buscarse una nueva vida, lejos del estigma que lo señalaba como hijo ilegítimo de una prostituta. Es decir, la empatía con los personajes ocurre en la medida que el relato es capaz de convencernos de que están sufriendo o deben ser protegidos, o cuando creemos que han sido tratados injustamente. De modo tal que cada diégesis modula su propio código ético para justificar que, pese a su naturaleza violenta y sus métodos abyectos, los héroes malvados son lo mejor de la historia, en tanto siempre existirá alguien mucho peor ${ }^{2}$.

Así, los relatos con antihéroes se construyen sobre una moralidad relativa en la que un personaje éticamente cuestionable se yuxtapone con otros explícitamente villanos y antipáticos para resaltar ciertas cualidades que puedan redimirlo (Mittel 2013). Aunque Nucky Thompson, el protagonista de Boardwalk Empire, se desarrolle abiertamente como un traficante de alcohol, un manipulador de los juegos de casino

2 El ecosistema de la maldad muchas veces requiere de la creación de localidades y emplazamientos ad hoc, como el distrito de Farmington en The Shield, la penitenciaría Oswald State en $O z$ o el condado de Charming en Sons of Anarchy (FX 2008-2014). 
y un político inescrupuloso, el público es capaz de verlo como el más digno por contraste con los otros personajes. Frank Underwood, la testa vistosa de House of Cards, es un lobista sagaz, un canalla sin bandera capaz de tejer y destejer los hilos necesarios que le permitan ascender en el poder político de los Estados Unidos. Sin embargo, es un personaje que se hace tolerable porque su descaro, su astucia y su tremenda habilidad de manipulación se ejercen en el marco de un sistema político que se describe como el tablero de juego de los más ricos y poderosos. Ahora bien, siguiendo a Mittel (2013), esto no los exime de juicio moral ni anula su condición de sujetos abominables. Por el contrario, pese a ello, la empatía y la complicidad continúan gracias a la fascinación que despierta imaginar experiencias que no se tendrá la oportunidad ni el coraje de vivir.

\subsection{La psicagogia del mal}

Como explica George Bataille en La literatura y el mal (1959), los seres humanos estamos dotados de una imaginación y unos deseos que exigen vivir más y mejor o peor de lo que vivimos; en todo caso, de una manera distinta, más intensa, más temeraria, incluso más insana. Las historias nacieron para que esa imposibilidad fuera posible, para que gracias a la ficción viviéramos todo aquello que las limitaciones de la realidad no permiten y que debió ser cercenado para que la coexistencia social fuera posible. De ahí que las historias de estos antihéroes resulten fascinantes, porque nos completan, porque están plagadas de aventuras — de atroces aventuras muchas veces - que podemos vivir vicariamente gracias al arte, en la pura ilusión.

Todo esto recuerda el poder psicagógico, "arrastrador de almas", del que hablaba Platón. Por 'psicagogia' se hace referencia a las emociones que producía el teatro gracias a las recurrencias poéticas típicas de los ensalmos, los rituales, la música y la poesía que, tanto por la forma como por el fondo, acababan cautivando las almas de los oyentes (López Eire: 2002). Esto era moralmente peligroso para Platón, pues consideraba que con esas herramientas el poeta era capaz de arrastrar al público a la sinrazón, apelando a la parte más baja del alma al provocar sentimientos de simpatía por los personajes que en la imitación poética manifestaban el sufrimiento o padecimiento de tales emociones.

Cuando llega el episodio titulado "Cornered", en la cuarta temporada de Breaking $\mathrm{Bad}$, el espectador confirma con terror que Walter White es plenamente consciente de su metamorfosis maligna: "Yo no estoy en peligro, Skyler [dice a su esposa]. iYo soy el peligro! Si un hombre abre la puerta y recibe un disparo, ¿piensas que soy yo? No. Yo soy el que toca la puerta".

A esta altura, la audiencia se pregunta: ¿cómo puedo estar del lado de este sujeto? Y, sin embargo, lo está y no querrá desentenderse hasta llegar al fin de ese tirabuzón perverso en que se ha convertido la vida del modesto profesor de Albuquerque. La gravedad moral que plantea Breaking Bad —el ejemplo por antonomasia-, lleva al público al límite del abismo para hacerle ver que también ha cruzado la línea, porque igual que Walter ha aceptado todas las coartadas, todos los móviles que han hecho de él un hombre malo. Pero aquello que sostiene el último tramo de Breaking Bad es la fascinación por el magistral carácter en que se ha convertido Walter White.

La perenne tensión entre el bien y el mal - especialmente el segundo filónencuentra en las ficciones del drama televisivo un espacio fecundo para seguir escribiendo su incombustible historia. Ahora cuenta con mayores posibilidades 
creativas y una ambición incontinente por contarlo todo, con un amplio espectro de temas, tratamientos y angulaciones que le permiten dar cuenta del horror, del vacío, del sinsentido, del estupor sincero que parece reconocer que el mal no siempre está en los otros, sino en uno mismo. Ahí están Lorne Malvo y Lester Nygaard, protagonistas de Fargo. El primero representa el mal en estado puro, la síntesis de lo perverso, un tipo cruel que disfruta honesta y ferozmente del dolor que es capaz de infligir. El segundo es un sujeto común que va perdiendo uno a uno los escrúpulos por voluntad propia, como un destino autoimpuesto que solo se alcanza con disciplina y que deja en claro que uno también tiene la libertad de convertirse en un depredador, si es capaz de superar la primera culpa.

La fecunda narrativa de las teleseries plantea nuevas perplejidades y expone las fallas de un sistema que lacera cualquier idea acerca del presente y del futuro. La naturalidad con que un niño toma un arma y mata, las carencias afectivas de un psicópata, las dudas honestas de un estafador o los miedos de un sicario, se presentan como radiografías descarnadas que relativizan las sanciones, desarticulan los valores e instalan la agonía en los espectadores, quienes no oponen resistencia porque acaso reconocen, sin saberlo, que la vida es esa permanente lucha contra lo imposible.

\section{Conclusión}

La confusión, el desequilibrio, la escisión, el desasosiego, la angustia, el desconcierto entre lo real y lo irreal, asoman cada vez más como tramas recurrentes. El gran tema que impulsa a las teleseries se acerca mucho al concepto de decadencia, una decadencia cultural, económica, social, finisecular y de resonancias apocalípticas, ilustradas muy bien por los zombis de The Walking Dead. Se observa una complacencia cada vez más clara por el defecto psíquico o somático, donde lo monstruoso o lo anormal se recubren de un intelectualismo ilusorio - como en Hannibal - que no disimula su irracionalismo y cuyo empaque en alta definición, su preciosismo formal y su estética deslumbrante parecen sugerir la complacencia por ignorar o evadir su propio declive.

Así las cosas, el viejo héroe moderno debe reinventarse, como si denunciara que lo social solo puede sostenerse a partir del simulacro. Si hiciéramos el ejercicio de encontrar lo heroico en las gestas de estos antihéroes, si operáramos en concordancia con los arcos dramáticos que dibujan personajes como Walter White, Tony Soprano o Don Draper, hallaríamos que lo heroico se resume en la figura del cínico.

Aunque el término alude a una búsqueda constante del beneficio personal, al margen de cualquier consideración moral y una completa despreocupación por el otro, estamos ante un cínico peculiar, uno que puede inscribirse en la línea de lo que planteaba Baltasar Gracián en El arte de la prudencia (2005): "varón desengañado, sabio virtuoso" (Gracián, 2005: 56). Es decir, un sujeto resignado a enfrentar los maltratos de un mundo en el que poco o nada de lo que ocurre se ajusta a la virtud y la razón, que sabe soportar los cambios de la fortuna, así como aprovecharse de ella cuando la ocasión resulta favorable. Para ponerlo en término de Sloterdijk (2003), un sujeto que está al tanto de la disonancia existente entre la mascarada ideológica y la realidad llana y terrena, pero que insiste en llevar la máscara porque es conveniente.

Este cinismo conoce de sobra la falsedad, sabe que el mundo se salió de control y despliega lo necesario para no ser perjudicado. "Es la falsa conciencia ilustrada, la 
conciencia infeliz que se sabe perdedora, pero no da su brazo a torcer y la emprende contra lo simbólico, reformulando su estatuto" (Sloterdjik, 2003: 137). De modo que en un tiempo donde los valores sociales y epistemológicos asoman como relativos, y donde no existe un único objetivo o valor que se yerga por encima de los otros, héroe será todo aquel que consiga administrar el caos.

“Sabes qué? [dice Walter a otro paciente con cáncer]. Cada vida viene con una sentencia de muerte. Por eso cada cierto tiempo vengo acá para hacerme un examen regular, sabiendo muy bien que una de esas veces, quizás hoy mismo, voy a escuchar malas noticias. Pero hasta entonces, ¿quién está a cargo? Yo. Es así como vivo mi vida". El desencanto moderno constituye una nueva actitud y exige un heroísmo distinto, el cual, aunque inspirado en sus formas probadas - heroísmo de la eficiencia, heroísmo de la fuerza moral, heroísmo estético-, empieza a inventarse a sí mismo (Birnbaum, 2004). Los héroes malvados dislocan el discurso moderno y craquean el establishment. Con ellos la realidad se subvierte, lo consciente y lo inconsciente colisionan y el statu quo es herido de muerte, aun cuando se retorne al equilibrio. Porque los planos que antes componían una realidad calculada ahora no pueden evitar mostrar un panorama distinto, lejos de las asepsias y los afeites de lo políticamente correcto.

Ya no se trata de producir nuevos procesos de cambio más o menos profundos, sino de ajustar la realidad a las expectativas el control del héroe. Y, en medio de todo esto, los criterios de verdad, la calificación moral, la pertinencia de la sanción, en fin, cualquier categoría absoluta se torna evanescente. Como señala Vattimo: "No hay una historia única, hay imágenes propuestas desde distintos puntos de vista, y es ilusorio pensar que haya un punto de vista supremo, comprensivo, capaz de unificar todos los restantes" (Vattimo, 1992: 76).

Los que campean en las teleseries no son ídolos forjados de acuerdo al deber ser, sino figuras marcadas por el no poder ser. El héroe de esta era televisiva es un cínico que proyectándose en sus posibilidades da significado al mundo y proyecta el mundo como suyo.

\section{Bibliografía}

Argullol, R. (1990). El héroe y el único. Barcelona: Destinolibro.

Bal, M. (1999). Teoría de la narrativa. Madrid: Cátedra.

Bataille, G. (1959). La literatura y el mal. Madrid: Taurus.

Bárcena, F. (2001) "El desencanto del humanismo moderno. Reflexiones sobre la identidad contemporánea", Aldea Mundo: Revista sobre Fronteras e Integración, vol. 5, núm. 10.

Birnbaum, A. (2004). Nietzsche: las aventuras del heroísmo. México, DF: Fondo de Cultura Económica.

Cappello, G. (2015). Una ficción desbordada. Lima: Fondo Editorial de la Universidad de Lima.

Cascajosa, C. (2006). "No es televisión, es HBO: la búsqueda de la diferencia como indicador de calidad en los dramas del canal HBO", ZER. Revista de estudios de la comunicación, núm. 21.

- (2009). "La nueva edad dorada de la televisión norteamericana", Secuencias: Revista de historia del cine, núm. 29. 
Echart, P. y Alberto N. García Martínez (2013). "Crime and Punishment: Greed, Pride and Guilt in Breaking Bad”. En: Alexandra Simon-López y Heidi Yeandle (eds.). A Critical Approach to the Apocalypse. Oxford: Inter Disciplinary Press.

Feuer, J. (2003). "Quality Drama in the US: The New Golden Age?” En: Hilmes, Michele (Ed.). The Television History Book. Londres: British Film Institute.

García Martínez, A.N. (2012). "Una máquina de contar historias”. En: Toro Martín, Juan Manuel de, Ignacio Bel y Alfonso Sánchez Tabernero (Eds.) La televisión en España. Informe 2012. Barcelona: Deusto/Uteca.

Gracián, B. (2005). El arte de la prudencia. Oráculo manual. Madrid: Temas de Hoy.

Goldmann, L. (1972). Para una sociología de la novela. Madrid: Ciencia Nueva.

Jitrik, N. (1997). Historia e imaginación literaria: las posibilidades de un género. Buenos Aires: Universidad de Buenos Aires.

Lyotard, J. F. (1994) La condición postmoderna. Informe sobre el saber. Madrid: Cátedra.

López Eire, A. (2002). Retórica clásica y teoría literaria moderna. Madrid: Arcos.

Lukács, G. (1979). Teoría de la novela. Barcelona, Grijalbo.

Mittell, J. (2007). "Film and Television Narrative". En Herman, David (Ed.) The Cambridge Companion to Narrative. Nueva York: Cambridge University Press.

Mittell, J. (2013). Complex TV: The Poetics of Contemporary Television Storytelling. Pre-publication edition. MediaCommons Press. Recuperado de http://mcpress.mediacommons.org/complextelevision (Fecha de acceso: 1/5/2014).

Pérez, X. (2011). “Las edades de la serialidad”, La Balsa de la Medusa, núm. 6.

Sloterdijk, P. (2003). Crítica de la razón cínica. Madrid: Siruela.

Thompson, R. (1997). Television's Second Golden Age: From Hill Street Blues to ER. Nueva York: Syracuse University Press.

Vattimo, G. (1990). La sociedad transparente. Barcelona: Paidós.

Villegas, J. (1978). La estructura mítica del héroe. Barcelona: Planeta.

Vogler, C. (2002 [1992]). El viaje del escritor: las estructuras míticas para escritores, guionistas, dramaturgos y novelistas. Barcelona: Ma Non Troppo. 